Case report

\title{
Yellow palms and feet in a child
}

\author{
Anca Chiriac ${ }^{1}$, Anca E. Chiriac ${ }^{2}$, Tudor Pinteala ${ }^{2}$, Elena Gologan ${ }^{2}$, Caius Solovan ${ }^{3}$, Piotr Brzezinski ${ }^{4}$ \\ ${ }^{1}$ Nicolina Medical Center, lasi, Romania \\ ${ }^{2}$ University of Medicine and Pharmacy "Gr. T. Popa”, lasi, Romania \\ ${ }^{3}$ University of Medicine Victor Babes, Timisoara, Romania \\ ${ }^{4} 6{ }^{\text {th }}$ Military Support Unit, Ustka, Poland
}

Received 6 November 2013, Accepted 2 December 2013

(C) 2013, Chiriac A., Chiriac A.E., Pinteala T., Gologan E., Solovan C., Brzezinski P.

(C) 2013, Russian Open Medical Journal

\begin{abstract}
The yellowish discoloration of the palms and skin is reported under different terms: xanthodermia, hypercarotenemia, carotenemia, carotenodermia. Yellow discoloration of the skin may be associated with carotenemia, hypothyroidism, diabetes mellitus, hyperlipoproteinemia, liver disease, and renal disease, meaning that carotenemia is not synonym with yellow skin, but rather one of the cause. We presented an 8 year-old boy with a yellow discoloration of the palms and soles, observed by the mother 3 weeks prior to medical examination. The discoloration was uniformly distributed, rather symmetrically, no nails changes, just a mild xerosis palmaris on the right hypotenar area. In lab investigations only were: hypercholesterolemia. The final diagnosis was xanthodermia in context of hyperlypoproteinemia type II A.
\end{abstract}

Keywords: child, skin disease, hypercholesterolemia, hyperlypoproteinemia

Cite as Chiriac A, Chiriac AE, Pinteala T, Gologan E, Solovan C, Brzezinski P. Yellow palms and feet in a child. Russian Open Medical Journal 2014 ; 3: 0107.

Correspondence to Dr Piotr Brzezinski. Address: Department of Dermatology, 6th Military Support Unit, os. Ledowo 1N, 76-270 Ustka, Poland. Phone (mobile): +48692121516. Fax: +48598151829. E-mail: brzezoo77@yahoo.com

\section{Case report}

An 8 year-old boy was addressed to us for a yellow discoloration of the palms and soles (Figures 1 and 2), observed by the mother 3 weeks prior to medical examination. At physical examination a yellowish pigmentation on the palms and soles was observed, no hyperkeratosis, no erythema, and no excoriations due to pruritus (which was not declared by the child or other member of the family). The discoloration was uniformly distributed, rather symmetrically, no nails changes, just a mild xerosis palmaris on the right hypotenar area. No other complains, no systemic symptoms, a very good health curve for the age.

A genetic examination was asked for the child and parents, he was the only child to the family; normal results were obtained.

Lab investigations were done and the only abnormal values were noticed for lipid profile: hypercholesterolemia; no signs of diabetes mellitus, no thyroid disturbances, no exaggerated carotene and/or orange food intake.

The final diagnosis was xanthodermia in context of hyperlypoproteinemia type II A, no treatment was recommended, and the child was referred to Diabetes and Nutrition Department for further investigations of hypercholesterolemia and follow-up.

\section{Discussion}

The yellowish discoloration of the palms and skin is reported under different terms: xanthodermia, hypercarotenemia, carotenemia, carotenodermia, xanthodermie cutanée in French literature

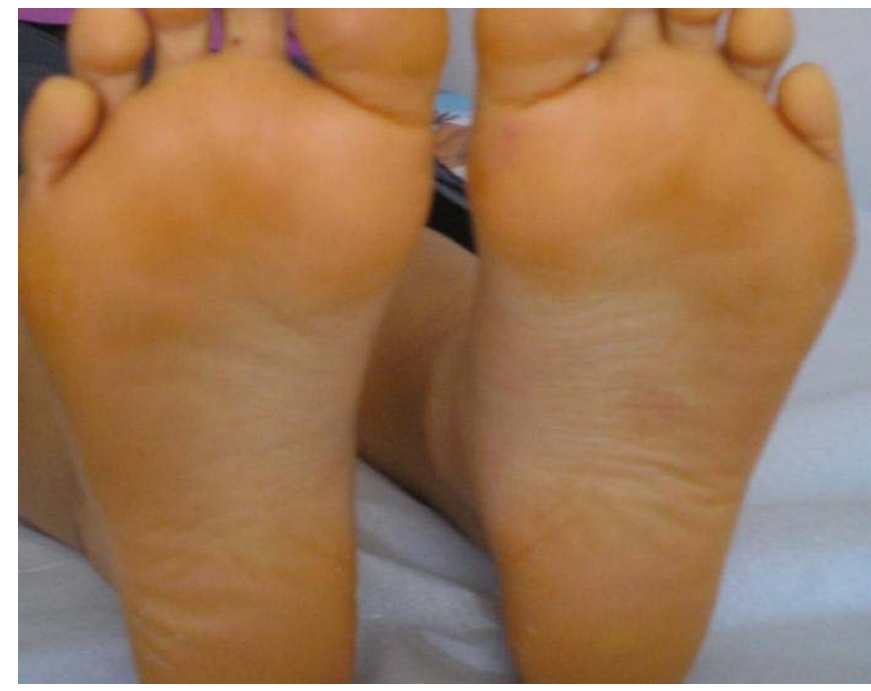

Figure 1. Yellow discoloration of the soles in an 8 year-old boy 
Table 1. Childhood hyperlipoproteinemia

\begin{tabular}{|c|c|c|c|c|c|c|}
\hline & \multicolumn{6}{|c|}{ Type } \\
\hline & I & IIA & IIB & III & IV & $\mathbf{V}$ \\
\hline Origin & exogene & & & & endogene & exogene \\
\hline Age of onset & childhood & childhood & adult & adult & adult & adult \\
\hline Familiary character & present & & & & & present \\
\hline Transmission & autosomal recesive & & & & & autosomal recesive \\
\hline Tryglycerides & +++ & normal & + & ++ & ++ & +++ \\
\hline Cholesterol & & +++ & + & + & normal & \\
\hline HDLC & & normal & low & & & low \\
\hline LDLc & & +++ & + & low & normal & \\
\hline VLDLC & & & & ++ & +++ & + \\
\hline Chilomicrons & + & & & & & + \\
\hline Tryglycerides/cholesterol & $>2.5$ & & & & & elevated \\
\hline Serum & clear with a creamy ring & clear & turbid & turbid & lactescent & lactescent with a cremy ring \\
\hline Xantomas & ++ & + & - & +++ & & + \\
\hline Hepatosplenomegaly & + & & & & & + \\
\hline Retinian lypemia & + & & & & & + \\
\hline Pancreatitis risk & + & & & & & + \\
\hline Xantelasma & & + & & & & \\
\hline Ateromatosis & & +++ & +++ & ++ & & \\
\hline Gerontoxon & & & + & & & \\
\hline Metabolic syndrome & & & +++ & & & \\
\hline Wavy character & & & ++ & & ++ & + \\
\hline
\end{tabular}

VLDLc, very low density lipoprotein cholesterol.

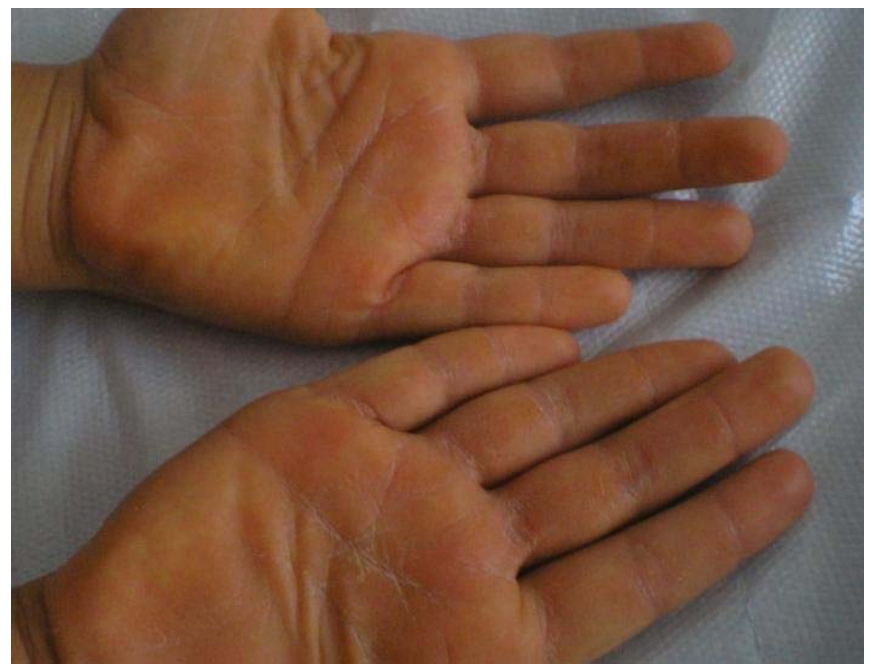

Figure 2. Yellow discoloration and hyperkeratosis of the palms in an 8 year-old boy

The first description appeared in 1925 in anglo-saxon publications while French Labbé in 1914 proposed the terminology of cutaneous xanthodermia [1]. Labbé' $s$ definition of xanthodermia was: discoloration of type golden yellow of the palms and soles in individuals suffering from severe diabetes mellitus and terminal stages of casexia, but also a manifestation observed in normal persons without any medical explanation. He thought, at that time, that the presence in the blood of a pigment: lipochrome (an equivalent of caroten) could explain the yellow aspect of the skin.

Even the term carotenodermia has its origin in Greek language: karôton means carotene and haïma blood. Hypercarotenemia signifies the presence in large quantity of carotene in the blood and carotenodermia high levels in the skin. Today the term xanthodermia/xanthoderma is more often used.
Yellow discoloration of the skin may be associated with carotenemia, hypothyroidism, diabetes mellitus, hyperlipoproteinemia, liver disease, and renal disease, meaning that carotenemia is not synonym with yellow skin, but rather one of the cause $[2,3]$.

Yellow palms and soles are associated with:

- Excessive food intake of carotene (especially from carrots, squash, sweet potatoes, oranges and spinach) is followed by the deposition of pigment in the tissues and the characteristic color. This is most seen in babies with too much carrot in alimentation (especially juice).

Columbia University's Health Services department point out that an intake of over $20 \mathrm{mg}$ of beta carotene, is enough to set off hypercarotenemia [4].

Hypercarotenemia can sometimes be an indicator of anorexia nervosa [4].

- Diabetes mellitus is well known today to cause yellow discoloration of the palms and soles [2, 5].

- Childhood hyperlipoproteinemia (Table 1);

- The various phenols, quinoline, diphenyls found in many hair lotions are photoactivated, and condensed to form polynuclear quinonoid compounds which are often colored and can induce transitory yellow coloration of the palms [6];

- The explosive trinitrotoluene (TNT) when it was handled for hours, by workers during the World War I, induced yellow skin over the palms; the women at those times were called "Canary Girls"--due to "nitro groups" within the TNT that reacted with melanin in the workers' skin (2008 paper in the Chemical Educator Journal);

- Sorafenib-Sunitinib are two drugs with known adverse reaction of yellow skin discoloration [4];

- Myxedema also can be associated with yellow skin and but not limited to the palms and soles [7]; 
- An intrigue correlation has been described between high cholesterol levels and hypothyroidism [8] but no parallel with yellow color of the skin from palms and soles.

Our case is interesting for the following reasons:

- It describes a peculiar and rare form of yellow discoloration of the skin limited to the palms and soles in a small child;

- Diabetes mellitus, exaggerated carrots intake, medication, thyroid dysfunction were not proven to be the cause.

- It is a hyperlipoproteinemia type II A, diagnosed by: elevated serum low-density lipoprotein cholesterol (LDLC) with normal high-density lipoprotein cholesterol (HDLc), clinical aspect (xanthodermia), clear serum at direct examination. Hyperlipoproteinemia type II A has two forms: primitive and secondary (associated with cholestasis or hypothyroidia). The familial form is caused by mutations of LDLc receptor gene. In homozigot forms the values of cholesterol are very high even in the first days of life and the medium survival rate is no more than 20 years due to cardiovascular risk. In heterozigot forms the survival is longer (about 30 years) and prognosis better. The polygenic forms have a moderate course and a good response to diet [9]

- Later in life gerontoxonum, xantelasma and xantomas may appear as a consequence of tissue storrage of cholesterol and the risk of premature onset of vascular abnormalities secondary to atheromatosis.

- Genetic analysis for familial forms are necessary for confirmation the diagnosis; follow-up of the patiens by laboratory investigations, elasticity tests for vessels and Doppler ultrasound for the risk of atheromatosis.

Conflict of interest: none declared.

\section{References}

1. Mikkelsen CS, Mikkelsen DB, Lindegaard HM. Carotinaemia in patient with excessive beta-carotene food-intake and dysregulated diabetes mellitus. Ugeskr Laeger 2009; 171(5): 315-316. (PMID: 19176161) [Article in Danish]

2. Li JN. Yellow Palms and Soles in Diabetes Mellitus. N Engl J Med 2006; 355(14): 1486. (doi: 10.1056/NEJMicm050780)

3. Brzeziński $P$, Bury $M$, Jagiełło-Wieczorek E. Coexistence yellow nail syndrome with systemic symptoms. N Dermatol Online 2010; 1(2): 1518.

4. Takita $Y$, Ichimyia M, Hamamoto $Y$, Muto M. A case of carotenemia associated with ingestion of nutrient supplements. J Dermatol 2006; 33(2): 132-134. (doi: 10.1111/j.1346-8138.2006.00028.x) (PMID: 16556283)

5. Puri N. A study on the cutaneous manifestations of diabetes mellitus. Our Dermatol Online 2012; 3(2): 83-86. (doi: 10.7241/ourd.20122.17)

6. Forman L. Pigmentation of the palms and scalp probably due to proprietary hair tonics, containing various phenols and phenolic derivatives. Br J Dermatol 1975; 93(6): 718.

7. Di Martino Ortiz B, Knopfelmacher O, Sacco A. Multiple tumoral lesions in an adolescent patient. Our Dermatol Online 2012; 3(4): 336341. (doi: 10.7241/ourd.20124.74)

8. Kolanuvada $\mathrm{P}$, Sujatha $\mathrm{Ch}$, Ambika $\mathrm{H}$. Disseminated superficial porokeratosis and anetoderma developing after acute pancreatitis. Our Dermatol Online 2012; 3(3): 228-230. (doi: 10.7241/ourd.20123.53)

9. Haney EM, Huffman LH, Bougatsos C, Freeman M, Fu R, Steiner RD Helfand M, Nelson HD. Screening for Lipid Disorders in Children and Adolescents [Internet]. Rockville (MD): Agency for Healthcare
Research and Quality (US); 2007 Jul. Report No.: 07-0598-EF-1. (PMID: 20722144)

Authors:

Anca Chiriac - MD, PhD, Head, Department of Dermatology, Nicolina Medical Center, lasi, Romania;

Anca E. Chiriac - student, University of Medicine and Pharmacy "Gr. T. Popa" Iasi, Romania;

Tudor Pinteala - student, University of Medicine and Pharmacy "Gr. T. Popa" lasi, Romania;

Elena Gologan - MD, PhD, Head, Department of Gastro-Enterology, University of Medicine and Pharmacy "Gr. T. Popa", lasi, Romania;

Caius Solovan - MD, Professor, Department of Dermatology, University of Medicine Victor Babes, Timisoara, Romania;

Piotr Brzezinski - MD, PhD, Head, Department of Dermatology, $6^{\text {th }}$ Military Support Unit, Ustka, Poland. 